\title{
Currículo e saberes escolares: ambiguidades, dúvidas e conflitos
}

M arćlio Souza Júni or ${ }^{*}$ Eliete Santiago*, M arcel o Tavares ${ }^{* *}$

Resumo: Inserindo-seentreosestudos queinvestigam a constituição dos saberes escolares, pelo olhar da Sociologia C rítica do C urrículo, a presente pesquisa apresenta-se como processo e produto de pesquisa qualitativa realizada na literatura eno campo, em documentoseentrevistas com dois professores dequatro diferentesdisciplinas curriculares, os quaispertenciam a escolas da RedeM unicipal deEnsino do Recife. Foi nesse processo que observamosa existência de mais ambiguidades, dúvidas e conflitos do que certezas na constituição dos saberes escolares, tanto nas disciplinas entendidas como secundárias, como Educação Física eArte, como nas disciplinas consideradas demaior prestígio, como Língua Portuguesa eM atemática.

Palavras-chave: escola; currículo; disciplinascurriculares; legitimação pedagógica

Curriculum and school knowledge: ambiguities, doubts and conflicts

Abstract: Among the onesthat investigate school knowledge build up, under the perspective of the Curriculum C ritical Sociology, thisstudy is presented as a qualitativeresearch process and product performed in literature and in the field, through documents and interviews with two teachers of four different curricular subject matters, who belonged to schools from the M unicipal Schools System in Recife. In this process we observed the existence of more ambiguities, doubts and conflicts than certaintiesin school knowledgebuild up, so much in subjects considered secondary, such as Physical Education and Arts, as in subjects of larger prestige, such as Portuguese and $M$ athematics.

Key words: school; curriculum, curricular subject matters; pedagogical legitimation.

* Professor da Licenciatura da Escola Superior de Educação Física da U niversidade de Pernambuco (ESEF-U PE) e do Mestrado Associado em Educação Física da U niversidade de Pernambuco e da Universidade Federal da Paraíba e membro do Grupo de Estudos Etnográficos em Educação Física e Esporte (Ethnós). Professor da Faculdade Salesiana do Nordeste (FASN E) e do Departamento de Educação da Universidade Federal Rural de Pernambuco, Brasil. m.souzaj@@uol.com.br e marciliosouzajunior@ pq.cnpq.br

** Professora do Programa de Pós-G raduação em Educação do Centro de Educação da U niversidade Federal de Pernambuco (CE/U FPE), Brasil. mesantiago@ uol.com.br

*** Professor da licenciatura da ESEF-U PE, do Mestrado Asso ciado em Educação Física U PE/U FPB e do Colégio de Aplicação da UFPE, membro do Grupo de Estudos Etnográficos em Educação Física e Esportes (Ethnós), Pernambuco, Brasil. mtavares19@ hotmail.com 


\section{Introdução}

A Escola, entendida como uma instituição social, responsabiliza-se por contribuir com a educação de homens e mulheres, crianças, jovens ou adultos. Sua educação diferencia-se da familiar, da sindical, da partidária, da religiosa, etc., podendo, talvez até devendo, refletir e interagir com essas modalidades educacionais, sem perder de vista o que lhe é específico, ou seja, favorecer seus sujeitos numa reflexão sistematizada, periódica, paulatina e contínua acerca dos conhecimentos produzidos pela humanidade, de forma a procurar superar a aleatoriedade, 0 acaso, o senso comum nas aprendizagens.

D iferentes elementos pedagógicos vão procurar materializar essa responsabilidade, sendo o currículo um deles. Este, mantendo interseção com os demais elementos, constitui os saberes escolares, fazendo uma seleção cultural e configurando-os como uma cultura escolar, devido às suas características peculiares. Essa configuração, ao longo do tempo, passou a ter uma força tão grande, principalmente em tempos modernos, que, além de selecionar elementos da cultura, passou a colaborar com a elaboração desta.

D iante desse entendimento, a vivência com a formação de professores temnos colocado em contato com sujeitos que, reiteradamente, questionam a constituição dos saberes específicos dessa escola e, consequentemente, da cultura por ela influenciada, levando-nos a perceber que esta, em distintas disciplinas, apresenta-se diferentemente no currículo da educação básica, ou seja, os saberes escolares não são constituídos da mesma forma nas várias disciplinas do currículo.

H á momentos em que se duvida da forma de estruturação dos saberes escolares, o que pode justificar situações marginalizadas de disciplinas no currículo escolar e também permite supor que tais saberes constituam objetos de luta por uma isonomia curricular.

Partindo do exposto, objetivamos compreender como se constituem os saberes escolares na generalidade e na totalidade do currículo da escola de educação básica e nas particularidades de algumas disciplinas curriculares, uma vez que pareciam existir mais ambiguidades, dúvidas e conflitos do que certezas na constituição desses saberes.

\section{Aspectos metodológicos}

Inserindo-nos entre os que investigam a constituição dos saberes escolares, pelo olhar da Sociologia C rítica do Currículo (Forquin, 1993; Goodson, 1995; M oreira, 1995; Silva, 1999) realizamos uma pesquisa qualitativa na literatura e no campo, em documentos e entrevistas com dois professores de quatro dife- 
rentes disciplinas curriculares, Educação Física (PEF1 e PEF2), Arte (PA1 e PA2), Língua Portuguesa (PLP1 e PLP2) e M atemática (PM 1 e PM 2), os quais pertenciam a escolas da Rede M unicipal de Ensino do Recife.

Procuramos reconhecer o Todo Escolar, inicialmente, na generalidade do currículo, captando os elementos comuns de caracterização das disciplinas ou de orientação a elas, e na totalidade curricular, confrontando como as especificidades, seja na semelhança ou na diferença, relacionam-se entre as diferentes disciplinas. Procuramos também reconhecer as especificidades nas particularidades das disciplinas curriculares, captando como essas absorvem e interferem na generalidade e na totalidade do currículo.

Assim, definimos, como fontes para coletar informações, os documentos considerados principais da Rede, que diziam respeito à constituição dos saberes escolares, e as falas de professores acerca de sua prática pedagógica no processo de constituição desses saberes.

A escolha dos professores deu-se numa fusão de intencionalidade e aleatoriedade. U m dos professores, selecionado aleatoriamente, teria que fazer parte da Equipe Pedagógica de sua área de formação e atuação docente. Essa equipe, na época da seleção dos sujeitos de pesquisa, era formada por professores que haviam sido indicados entre os pares para assumir a responsabilidade de acompanhamento da disciplina nas escolas e a condução dos Encontros Pedagógicos $M$ ensais (EPM S) ${ }^{1}$. 0 número de membros de uma Equipe Pedagógica variava nas diferentes disciplinas, podendo ser constituída de duas a quatro pessoas. 0 critério para a seleção do segundo professor foi exatamente o contrário, ou seja, não poderia fazer parte da Equipe Pedagógica, tendo sido escolhido aleatoriamente entre os docentes, numa listagem nominal da Secretaria de Educação.

A delimitação das disciplinas deu-se porque estas são expressões de posições distintas na organização curricular da escola de educação básica. Língua Portuguesa e $M$ atemática, por serem tradicionalmente reconhecidas como disciplinas de maior prestígio e importância no currículo. Arte e Educação Física, contrariamente, por serem consideradas como secundárias, de menor relevância.

0 utra razão que nos levou a escolher as disciplinas foi o fato de estas trabaIharem, de certa forma, com a dimensão das linguagens. M uito embora a atual legislação educacional não coloque a M atemática, assim como coloca as outras

1. Uma espécie de reunião entre os professores de cada disciplina para reflexões pedagógicas sobre a ação docente na Rede Municipal de Ensino, como também para realização de estudos e ações coletivas (leitura e produção de textos, apresentações de trabalhos de pós-graduação, relatos de experiências, debates sobre as ações da gestão central, preparação de atividades extras para os alunos - passeios, jogos, feira de conhecimento, projetos, etc). O s professores possuíam carga horária semanal acumulada destinada especificamente para a realização mensal de reunião nas instâncias da própria Secretaria de Educação. 
três, na Área de Códigos e Linguagens, mas, sim, na Área das Ciências da $\mathrm{N}$ atureza², muitos estudos reconhecem e até defendem o papel daquela como linguagem ${ }^{3}$.

Ainda na escolha dessas disciplinas, vimos que, convencional e vulgarmente, na Língua Portuguesa e na M atemática, o ler, o escrever e o contar configuraram-se como o essencial na cultura escolar, sendo compreendidos, inclusive, como os conteúdos do domínio intelectual. Por outro lado, na Educação Física e na Arte, há certo menosprezo pelos seus conteúdos de ensino, inclusive por trabalharem, em alguns momentos, com os elementos do domínio corporal.

Assim, foi coletado, por via de um roteiro de entrevista semiestruturada, 0 que diziam dois professores de cada disciplina acerca de sua prática pedagógica na constituição dos saberes escolares específicos de sua área de conhecimento, assim como de suas ações no currículo de uma forma geral.

Para o tratamento e a análise de dados coletados na literatura, nos documentos e nas falas, tendo como referências os estudos de M inayo (1996) e Bardin (1988), usamos a análise de conteúdo do tipo categorial por temáticas, a qual funciona por desmembramento de texto em unidades e categorias para posteriores reagrupamentos analíticos.

\section{A constituição dos saberes escolares}

Vimos que as disciplinas escolares aqui investigadas vivem, em suas particularidades, um processo contínuo e contraditório por legitimação pedagógica, em torno da isonomia curricular. $\mathrm{N}$ a totalidade curricular, constatamos que elas se estabelecem em meio a relações de tensões recíprocas, buscando reconhecimento e fazendo-se reconhecer frente aos sujeitos e às instâncias pedagógicas da política curricular.

Compreendendo que os saberes escolares se constituem num processo de seleção, organização e sistematização do conhecimento, mesmo sabendo que este se dá de forma contínua e dialética, as unidades de contexto e de registro caracterizaram cada situação desse processo, configurando-as como categorias empíricas.

2. Sugerimos consultar as diretrizes curriculares para o Ensino Médio, Resolução n.ํ 03/98, da Câmara de Educação Básica do Conselho N acional de Educação.

3. O s Parâmetros $\mathrm{C}$ urriculares $\mathrm{N}$ acionais, os quais podemos considerar como desdobramentos da política educacional que deu o tom da atual Lei de Diretrizes e Bases da Educação $\mathrm{N}$ acional (LDB) - Lei 9394/96 (Brasil, 1996), apresentam a M atemática também como linguagem (Brasil, 1999, 2000). C arvalho (1996) reconhece, em suas observações sobre os currículos de Matemática, uma proposta que chama a atenção para esse papel. Moura (2006) defende que um dos desafios para 0 ensino da Matemática é levar os alunos a aprenderem, mais do que códigos e regras. É aprender a linguagem matemática como método de conhecer e transmitir o que conhecem.

Pro-Posições, Campinas, v. 22, n. 1 (64), p. 183-196, jan./abr. 2011 
$\mathrm{N}$ a seleção do conhecimento, identificamos diferentes fontes para suas escoIhas, tais como a proposta pedagógica, o livro didático, a formação continuada e as orientações legais, a exemplo dos Parâmetros Curriculares N acionais; percebemos também a relevância dessa seleção, ora por justificativas do uso social dos conteúdos de ensino, ora por preparação para o vestibular; e ainda pelas compreensões presentes nos elementos da teoria pedagógica orientadores de teorizações e de diferentes concepções de escola, disciplina, professor, aluno.

$\mathrm{N}$ a organização do conhecimento, observamos que as condi ções escolares para a documentação e o acompanhamento do planejamento, o conhecimento da turma e 0 uso de recursos e instalações interferem no arranjo dos saberes. D a mesma forma que a tipologia e a quantidade dos conteúdos da disciplina, o tempo estrutural para sua organização, seja em série ou ciclo, condicionam a disposição do conhecimento.

$\mathrm{N}$ a sistematização do conhecimento, verificamos que os princípios, os métodos e os procedimentos dos aspectos metodológicos, assim como os elementos referentes ao tempo necessário às aprendizagens dos alunos e seus métodos e procedimentos de avaliação contribuem na constituição dos saberes escolares.

N este texto, fizemos opção por apresentar os dados e as análises, focalizando a fonte - especificamente a proposta pedagógica - e a relevância para a seleção; a disposição do conhecimento, perante a organização, e os aspectos metodológicos diante da sistematização.

Seleção dos saberes escolares: a proposta pedagógica como fonte e a legitimação como critério de relevância

Procuramos confrontar as particularidades das disciplinas escolares, na intenção de evidenciar as ambiguidades, as dúvidas e os conflitos existentes na constituição dos saberes escolares, principalmente nas tensões em torno da busca por uma isonomia curricular. Essa análise de confrontação na totalidade curricular esteve orientada pelas polêmicas em torno da constituição dos saberes escolares, averiguando o lugar e o grau de prioridade, prestígio, importância e privilégio de algumas disciplinas, em contrapartida à secundarização, ao desprestígio, à menor relevância e à banalização de outras.

A Proposta Pedagógica da Rede M unicipal do Recife (Recife, 2002, 2003) é a referência de base para a seleção dos saberes escolares, pois todos os professores, de todas as disciplinas, afirmam usá-la como fonte para a escolha dos conteúdos de aula. Ainda assim, as particularidades vão fazer com que a relação de cada disciplina com a Proposta se diferencie.

Em Educação Física, as professoras usam a Proposta como base, mas têm nos Parâmetros Curriculares N acionais (PCN) uma fonte importante de consulta para essa seleção. Eu pego no Coletivo de Autores, que falam da questão 
cultural. M inha base é o coletivo de autores. É o que mais se adapta à proposta da Rede [...] Eu também, apesar de não ser bem aceito aqui na Rede, uso os PCN . Eu uso como referência (PEF1).

Já as professoras de Arte reconhecem a Proposta Pedagógica como base, porém demonstram certo desdém e, por vezes, até negligência por essa fonte.

Tem aquela proposta... Como équechama?É atéum caderninho branquinho, já esqueci o nomedele Tem arte, tem Educação Físca também. Eu olho tudo. Porque, na realidade, quando eu trabalho, eu não sigo sóum material, eu vou colhendo vários $E$ vou olhando, porqueémaisinteressantepara eu trabal har. Tem ocaderninho que a prefeitura dá, sevocêtivessefalado, eu tinha trazido, pegue hoje o meu. Existe, existearte, português, educação física... (PA2).

As professoras de Língua Portuguesa e os professores de M atemática, além de tomarem a Proposta como base, têm-na como central na estruturação de sua prática pedagógica e não apenas na seleção, utilizando-a também na organização e na sistematização do conhecimento, ou seja, a Proposta Pedagógica ocupa centralidade na constituição dos saberes escolares, pois nela os professores buscam as competências de sua área, de sua disciplina específica, dos eixos dos saberes, os conteúdos, as referências nas teorias pedagógicas que orientam a concepção de sociedade, de formação humana, de escola, de seu objeto de estudo específico, e os fundamentos metodológicos.

O lha, nóstemos, na prefe tura da cidadedo Recife, uma proposta pedagógica e, a partir dessa proposta pedagógica, équea gentetem toda uma relação deconteúdosecompetênciasquea genteforma no cidadão. Então, a partir da proposta pedagógica éondeeu busco essa parte. Agora, fora isso, eu tenho todo um outro, outra literatura, outra bibliografia em queeu busco novasalternativas detrabaIho com o aluno. [...] Então eu busco na proposta pedagógica ebusco em outrasfontestambém (PLP2).

O utro aspecto que vai interferir, e até mesmo condicionar a seleção do conhecimento nas diferentes disciplinas é a relevância atribuída aos seus saberes escolares. 0 entendimento dessa relevância remete-nos ao movimento de legitimação pedagógica ${ }^{4}$ vivido por cada uma no currículo. D entre as reflexões acerca da legitimação pedagógica de um saber escolar, vimos, nas falas dos professores, que surgem diferentes tipos.

4. U samos o termo "legitimação" ao invés de "legitimidade", po is, ainda que se refiram a um mesmo fato, apresentam tênues diferenças no sentido. Primeiro, porque a legitimidade, muitas vezes, é associada à legalidade, pois se aplica à qualidade de um estado de direito, autenticidade, genuinidade, conformidade com a lei. Segundo, porque a legitimidade também é usada para 
Aparece a legitimação instrumental, que traz fundamentos que demonstram a relevância da disciplina em virtude de alguma situação prática para aplicação imediata do conhecimento, indicando a utilidade dos saberes para as atividades das crianças e dos adolescentes, inclusive na própria escola.

Surge também, sem descartar a primeira, a legitimação propedêutica, que apresenta argumentos de aplicação para uma vida futura, uma vida adulta, principalmente relacionada ao mundo do trabalho.

Aparece ainda a legitimação social, que não descarta as duas anteriormente citadas, que argumenta em favor de uma disciplina entendida como um corpo de conhecimento que permite receber, perceber o mundo que nos cerca, assim como exprimir, intervir nesse mesmo mundo. N este último tipo, a disciplina não perde sua legitimação instrumental - imediata - e sua legitimação propedêutica - futura -, mas está correlacionada, de forma mais explícita, aos aspectos coletivos, multidimensionais, reflexivos, de ordem política e social.

Surge ainda, em alguns discursos de algumas disciplinas, a legitimação afetiva, indicando o uso de recursos afetivos de apelos pessoais na relação professor-aluno, relacionando-se ao prazer imediato em fazer a aula que, por muitas vezes, termina por justificar 0 atendimento às vontades dos alunos, ou, pelo menos, de alguns.

$\mathrm{N}$ a Educação Física, a legitimação afetiva é um importante critério para a seleção dos conteúdos. Planejamento? Ele vai ser a última coisa que ele vai achar. Entendeu? Ele quer atender a necessidade dos meninos naquele momento. Que é estar em movimento (PEF2).

Esse tipo de legitimação pedagógica vai ser presença marcante também com as professoras de Arte, afirmando que o interesse dos alunos é um forte argumento para definir a seleção dos saberes.

Por exemplo, uma 7ạ série, queera extremamentemusical, a única coisa queelesquerem étocar edançar. Como équeeu vou dar aula deteatro? Já mudei, já mudei. Aí, eu estou trabalhando com eles.

expressar compatibilidade com os padrões sociais fundamentados na ética ou mesmo pelo reconhecimento da opinião pública (Souza Júnior, 1999). Já a legitimação se expressa num movimento de incompletude, como algo que busca justificação. No sentido aqui exposto, as diferentes disciplinas escolares vivem um constante movimento de busca por reconhecimento no currículo escolar, almejando certa isonomia curricular, certo respeito, direito e dever frente aos sujeitos e instâncias pedagógicos. U ma legitimação pedagó gica é continuamente intencionada, num movimento histórico e dialético, de construção e desconstrução de uma disciplina escolar. Essa legitimação configura-se diferentemente, de acordo com o momento e a concepção pedagógica que orientam a escola na generalidade do currículo ou nas particularidades das disciplinas (Souza Júnior, 2007). 
Agora mesmo, eu planeje ecomprei um DVD, deum grupo chamado Thetheicho, um grupo americano, queeu quero ver sea gentevai trabalhar... N o pagode, queelesadoram pagode, não sei o quê... e músca brega. M aseu quero quea gentefaça um concurso decoreografias. Então, eu direcionei. Então essa 7ạ saiu do teatro (PA1).

Em Língua Portuguesa e M atemática, as legitimações instrumental, propedêutica e social ocupam maior grau de importância na seleção dos saberes escolares. 0 reconhecimento dado aos interesses dos alunos aparece como forma de contextualizar o conhecimento, dar maior significado e motivação ao ensino, mas não como critério de legitimação afetiva.

Em alguns conteúdos, eu tenho uma intervenção maisimediata para o nosso dia-a-dia, há também conteúdosem queeu não tenho uma intervenção, posso passar o resto da vida, e perguntar: para queservei sso? O ra para nada. I sso não ésó em matemática, maseu tenho em tantasoutrascoisas (PM 1).

Primeiro, para formar sua bagagem, formar o conhecimento para queele possa, realmenteacompanhar os seusestudos, numa série subsequente. E possivelmentepara a sua vida lá fora (PM 2).

A proposta pedagógica de uma instituição ou de uma Rede de Ensino e a legitimação pedagógica das disciplinas curriculares, mesmo que de forma diferenciada em cada uma dessas, interferem diretamente na seleção dos saberes escolares.

O rganização dos saberes escolares: disposição do conhecimento

As disposições e os arranjos dos saberes escolares seguem critérios de hierarquização, sequência e graduação; no entanto, os professores não assumem essa tarefa.

N a Educação Física, há a afirmação de que o diferencial de outras disciplinas em relação a ela é que em outras há uma organização de conteúdos instituída pela tradição e presente nos livros didáticos.

Tem isso, queéo diferencial. Asoutras disciplinastêm livro didático, têm uma organizaçãojá instituída deconteúdos que podem ser mudados, masquejá foram insti tuí dos pela tradição, quevem lá da I dade M édia, que vem lá de não sei aonde, do trívio, do quadrívio... E vem sendo complementado, não é? Educação física é uma história recente(PEF1). 
Há depoimentos que indicam que a ordenação, a repartição e a dosagem dos conteúdos em Arte são feitas por intuição.

Rapaz, eu não tenho critério nenhum, eu não tenho critério ne nhum, eu vou ser franca com você Eu acho queuma dascoisaséa prática na sala de aula, a intuição, com um pouco de lei turinha aqui, uma leiturinha ali, eu vou meorganizando. Por exemplo, eu não apresentaria para eles, por exemplo, um filmemaisforteque tenha cena desexo, eu não faria isso, tem queter o crivo. Assim, eu respeito mui to pela idade, eu vou pela idade, eu avalio, eu analiso, vejo o queelesconversam, o queéqueelesfalam, o queéqueeles sabem. Aí eu vou, com asminhascoisas, queeu tenho, organizando eadequando, agora... Eu não poderia Ihedizer aqui, que conheço teorias deninguém, deinteligência, deconhecimentos, denada, sabe? Eu sempreetou deondeelesetão, eu dou maisum pouquinho, massemprecom muito respeito (PA1).

Particularmente, nas disciplinas de Língua Portuguesa e M atemática são os livros didáticos que também oferecem uma disposição pronta aos professores e aos alunos.

Antigamente, basicamente, o professor... N ão só antigamente, há uma boa partedo professor queainda faz uma sequência deconteúdos, atreladosao queo livro texto diz. Eu tenho quetrabalhar eses conteúdosessa coi sa toda. M uito embora oslivrosqueadotamosna Redejá têm o viés da educação matemática, que eles têm os eixos temáticosatreladosetudo; então, o professor fica nessa eminência, de seguir a sequência do livro texto, no meu caso espećfico, eu faço de acordo com a necessidadequeeu tenho do trabalho da turma, baseado no queeu meprogramei, lidando com competências, certo? (PM 1).

A disposição do conhecimento, ou seja, a estruturação desse, no tempo e no espaço escolar, é uma importante dimensão da organização dos saberes escolares. $\mathrm{N}$ essa, o livro didático, ainda que venha sendo elaborado, selecionado, usado de forma menos convencional, configura-se como importante referência para a hierarquização, a sequência e a graduação do conhecimento.

Sistematização dos saberes escolares: aspectos metodológicos

Vimos que é comum a busca de uma diversidade metodológica entre os professores, sendo as condições escolares, e em especial, os recursos pedagógicos, um fator condicionante.

No caso de Educação Física, a precariedade ou a inexistência de um ambiente específico de aula define a estruturação da prática pedagógica, pois as 
condições climáticas de sol e chuva determinam a seleção, a organização e a sistematização dos saberes escolares.

O lhe em relação ao local, émuito prejudicado, por não ser coberto, o fato denão ter coberta dificulta muito, no período de chuva, e mermo o sol. A aula das 11 horasémuito prejudicada, essasaulas dosúltimoshorários. Em relação ao material, a diretora compra, por insistência da gente, algum material. Ela comprou no ano passado, masesseano ela não tinha dinheiro para comprar, então fi cou o material... A sobra do ano passado, quejá está velho. Bolas velhas, o material já quebrado, arcosquebrados... Então, assim, a gentetem quecontar com a ajuda mermo da gestão, dela conseguir uma verba espećfica para comprar o material, a gentefica nessa dependência (PEF1).

As professoras de Arte são as que mais se queixam da ausência de materiais específicos para as suas aulas e da desorganização da escola em relação a eles, e isso se dá muito fortemente, pois os locais e os materiais didáticos são também conteúdos de aprendizagens.

É o que eu tefalei, à proporção queeu vou conseguindo material novo, porque a minha dificuldade maior é material de apoio, filmes, imagens, material queeu possa trabalhar com o aluno. Até sevocêprecisar tirar uma cópi a deum livro, hojeem dia não pode, éproibido; então, vocêtem a maior dificuldade, eisso meirrita profundamente(PA2).

As professoras de Língua Portuguesa e os professores de M atemática são os que menos se queixam da precariedade de recursos pedagógicos, principalmente por terem no livro didático seu material principal.

...pelo menosna escola em queeu trabal ho, tenho, em relação a material, um apoio, não só eu, mastodo professor lá. A genteéassim... É muito subsidiado quantoa material. Só para dar um exemplo, antes mesmo da prefeitura ter o kit, quefoi dado ao aluno, quecontinha todososmateriais, no caso espeáfico dematemática, esquadro, régua, transferidor etudo mais, eu já havia solicitadoà eccola quecomprasse ea escola, dentro da medida do possível, comprou essekit ea gente tinha e eu já trabalhava com eleantesdosoutros Eu solicitei, por exemplo, a compra de máquina de calcular, para fazer trabal ho; então, a escola, dentro da medida, comprou (PM 1).

M esmo com uma possibilidade de uso de diferentes metodologias, os professores ficam condicionados em função do ambiente e do recurso pedagógico para a sistematização dos saberes escolares. 


\section{Considerações finais}

Com os fundamentos expressos nas nossas opções e construções metodológicas e nas análises dos dados da literatura e do campo, percebemos que a constituição dos saberes escolares se dá num movimento de autonomia relativa, diante da influência reprodutora dos fatores sociais mais amplos; portanto, também não se isola desta, numa produção meramente singular e única.

$N$ essa constituição, a generalidade e a totalidade do currículo escolar e as particularidades das disciplinas escolares estão, portanto, circunscritas a esse movimento, ao mesmo tempo que produzem elementos para sua estruturação, são transformados por ela, sendo os sujeitos educacionais aqueles que usufruem, elaboram, materializam e transformam a educação escolar.

0 currículo, então, é tanto objeto de apropriação e assimilação particular e individual, social e coletiva do conhecimento acumulado na história da humanidade, como expressão da força de trabalho, do caráter produtivo dessa humanidade. Sendo assim, é necessário superarmos, cada vez mais, os currículos prescritivos normativo-racionalistas e construirmos um currículo emancipatório, que reconhece, propicia e solicita o potencial produtor dos sujeitos educacionais.

A partir desses achados e dessas análises, pensamos que uma proposta pedagógica precisa ser compreendida como uma fonte epistemológica para a seleção, a organização e a sistematização dos saberes escolares. U ma proposta pedagógica de rede ou de escola deve ser objeto de referência da teoria e da prática pedagógica, oferecendo os fundamentos à ação docente diante da constituição dos saberes escolares.

A pesquisa mostrou que a seleção e a organização dos saberes escolares têm sido, durante muito tempo, realizadas por especialistas em currículo ou em cada disciplina escolar, sem a participação do professor. Esses saberes foram, e ainda são, bastante definidos previamente em planos curriculares, seja em formato de política educacional ou mesmo de livro didático. Os professores, portanto, não conseguem entender e/ou explicar a hierarquia entre conteúdos tratados como essenciais e secundários, nem a estruturação lógica e metodológica dada aos saberes escolares. M uitos professores terminam por utilizar o livro didático como fonte para essa seleção e organização na forma de tarefa a ser cumprida, apesar do avanço da política de elaboração, editoração, distribuição e uso de tais materiais didáticos.

Esses livros não devem ser encarados como fonte epistemológica para o currículo escolar, apesar de também terem tais fundamentos. O s livros devem ser recursos pedagógicos dos sujeitos educacionais na apropriação e na produção do conhecimento e não o contrário. Por vezes, os livros didáticos de cada disci- 
plina escolar orientam e até determinam o currículo, ou seja, a seleção, a organização e a sistematização dos saberes, fazendo com que professores e alunos, simplesmente, sigam-nos como manuais.

É evidente a influência do processo de legitimação pedagógica das diferentes disciplinas do currículo da educação básica na constituição dos saberes escolares. M esmo que a escola, convencionalmente, possua um traço propedêutico e instrumental, e ainda que a construção de um ambiente pedagógico amistoso, alegre e afetuoso permeie a intencionalidade e a ação docentes, as disciplinas curriculares necessitam construir sua legitimação pedagógica sem precisar lançar mão de recursos afetivos de apelos pessoais. Em contrapartida, apelos autoritários, coercitivos, ameaçadores, mesmo que se deem de forma generalizada e impessoal, também precisam ser abandonados.

É importante que, nesse processo, não se recorra à legitimação afetiva, mas consolide-se a legitimação social das diferentes disciplinas. As legitimações instrumental e propedêutica devem ser reestruturadas, justificando a instrumentalização imediata e a formação futura, não para uma inserção adaptativa do aluno ao mercado de trabalho nem para uma preparação mecanicista, visando aos vestibulares de acesso a uma formação em nível superior.

A legitimação pedagógica deve justificar os saberes e as competências para a formação humana, para sua participação crítica, solidária e criativa na vida.

Vimos que os saberes escolares são constituídos numa grande dependência das condições escolares e entre elas se destacaram os materiais e as instalações disponíveis, chegando a gerar sua aparição ou exclusão em função da disponibilidade de recursos didáticos. M esmo que tal elemento seja imprescindível na constituição dos saberes escolares, pois circunscreve sua exequibilidade, estes não poderiam ficar à mercê das disponibilidades de recursos.

De fato, os recursos didáticos são bem definidores no tratamento dos conteúdos no ensino de algumas disciplinas escolares, como Educação Física e Arte; são também conteúdos pedagógicos, pois o recurso que pinta e é pintado, o que veste e é vestido, o que esculpe e é escul pido, o que expõe e é exposto, ou seja, o pincel, a tinta, o papel, o texto, o livro, a tela, o barro, a escultura, 0 quadro, o desenho, a fotografia, o vídeo, a imagem, o som, a voz, o gesto, 0 corpo... são objetos pedagógicos do conhecimento, são objetos de aprendizagem dos alunos, de apropriação dos saberes, sendo, portanto, não apenas recursos pedagógicos, mas também essência da ação pedagógica entre os sujeitos educacionais.

Por certo, se os professores de disciplinas como Língua Portuguesa e M atemática ampliassem suas ações, usando esses recursos, mesmo como materiais didáticos, suas aulas teriam, no mínimo, mais dinamicidade e atratividade, podendo levar os alunos a aprendizagens mais significativas e prazerosas. 
Enfim, vimos que as diferentes disciplinas escolares aqui investigadas vivem um processo de busca por legitimação pedagógica, um movimento contínuo e contraditório de construção de uma isonomia curricular, mas não no sentido de igualdade, pois isso não seria possível, já que as disciplinas, nas particularidades, apresentam uma grande diversidade de elementos singulares. No entanto, há, na generalidade curricular, elementos que orientam diferentes disciplinas no cumprimento das atribuições e das possibilidades pedagógicas e na conquista delas. E, na totalidade do currículo, essas atribuições e possibilidades se estabelecem em meio a relações de tensões recíprocas, buscando reconhecimento e fazendo-se reconhecer frente aos sujeitos e às instâncias pedagógicas da política curricular.

Foi nesse processo que observamos a existência de mais ambiguidades, dúvidas e conflitos do que certezas na constituição dos saberes escolares, tanto nas disciplinas entendidas como secundárias - Educação Física e Arte, por exemplo - como nas disciplinas consideradas de maior prestígio, como Língua Portuguesa e M atemática. As ambiguidades, as dúvidas e os conflitos dizem respeito à estruturação do currículo escolar da educação básica.

\section{Referências bibliográficas}

BARDIN , L. Análisedeconteúdo. Lisboa: Edições 70, 1988.

BRASIL. M inistério daE ducação. Lei deD iretrizese Bases da Educação N acional - Lei n.ำ 9394/96. Braślia, 1996.

BRASI L. M inistério da Educação. Secretaria deE ducação M édia eTecnológica. Parâmetros CurricularesN acionais- PCN : ensino médio. Braślia: M EC/SEM T, 1999.

BRASI L. M inistério daE ducação. SecretariadeEducação Fundamental. ParâmetrosC urriculares Nacionais- PCN : 5a a 8a séries. Braślia: M EC/SEF, 2000.

CARVAL H O , J. P. de. O bservações sobreos currícul os de matemática. Presença Pedagógica, Belo H orizonte, v. 2, n. 7, p. 55-63. jan./fev. 1996.

FO RQ U IN , Jean-C laude. Escola ecultura: as bases sociais eepistemológicas do conhecimento escolar. Porto Alegre: Artes M édicas, 1993.

GO O DSO N , I. F. Currículo: teoria ehistória. Rio de aneiro: Vozes, 1995.

M IN AYO , M . C . deS. 0 D esafio do Conhecimento: pesquisa qualitativa em saúde. São Paulo Rio deJ aneiro: $\mathrm{H}$ ucitec - Abrasco, 1996.

M OREIRA, A. F. B. Currículoseprogramasno Brasil. Campinas: Papirus, 1995.

M O U RA, M . 0 . de. Saberes pedagógicos e saberes específicos: desafios para o ensino da matemática. In: SI LVA, A. M . M . et al. (0 rg.). N ovassubjetividades, currículo, docência equetões pedagógi casna perspectiva da inclusão social. Recife: Endipe, 2006. p. 489-504. 
RECIFE (Prefeitura). Secretaria de Educação. D iretoria G eral do Ensino. Proposta Pedagógica da RedeM unicipal deEnsino deRecife construindo competências. Recife: SecretariadeEducação, 2002. Versão preliminar.

RECIFE (Prefeitura). Secretaria de Educação. Diretoria Geral do Ensino. Tempos de aprendizagem, identidadecidadã eorganização da educação escolar em ciclos. Recife: Secretaria de Educação/Edufpe, 2003.

SILVA,T.T. da. D ocumentosdeidentidade: umaintrodução àsteoriasdo currículo. Belo H orizonte: Autêntica, 1999.

SO UZA JÚ N IOR, M . 0 saber e o fazer pedagógi cos a Educação Física como componente curricular... ? ...isso éH istória! Recife: Edupe, 1999.

SO UZA JÚ NIO R, M. A constituição dos saberes escolares na educação básica. 2007. Tese (D outorado) - U niversidadeFederal dePernambuco, Recife: U fpe, 2007.

Recebido em 09 de março de2010 eaprovado em 24 dejunho de2010. 